\title{
Exacerbated Craving in the Presence of Stress and Drug Cues in Drug-Dependent Patients
}

\author{
Kenzie L Preston ${ }^{*,}$, William J Kowalczyk', Karran A Phillips', Michelle L Jobes', Massoud Vahabzadeh², \\ Jia-Ling Lin², Mustapha Mezghanni' ${ }^{2}$ and David H Epstein' \\ 'Clinical Pharmacology and Therapeutics Research Branch, Intramural Research Program, National Institute on Drug Abuse, Baltimore, MD, USA; \\ ${ }^{2}$ Biomedical Informatics Section, Administrative Management Branch, Intramural Research Program, National Institute on Drug Abuse, Baltimore, \\ MD, USA
}

\begin{abstract}
In addiction, risk factors for craving and use include stress and drug-related cues. Stress and cues have additive or more-than-additive effects on drug seeking in laboratory animals, but, surprisingly, seem to compete with one another (ie, exert less-than-additive effects) in human laboratory studies of craving. We sought heretofore elusive evidence that human drug users could show additive (or more-than-additive) effects of stress and cues on craving, using ecological momentary assessment (EMA). Outpatients $(N=182)$ maintained on daily buprenorphine or methadone provided self-reports of stress, craving, mood, and behavior on electronic diaries for up to 16 weeks. In three randomly prompted entries (RPs) per day, participants reported the severity of stress and craving and whether they had seen or been offered opioids, cocaine, cannabis, methamphetamine, alcohol, or tobacco. In random-effects models controlling for between-person differences, we tested effects of momentary drug-cue exposure and stress (and their interaction) on momentary ratings of cocaine and heroin craving. For cocaine craving, the Stress $\times$ Cue interaction term had a positive mean effect across participants ( $M=0.019$; CL95 $0.001-0.036$ ), denoting a more-than-additive effect. For heroin, the mean was not significantly greater than 0 , but the confidence interval was predominantly positive $(M=0.019$; CL95 -0.007-0.044), suggesting at least an additive effect. Heterogeneity was substantial; qualitatively, the Stress $\times$ Cue effect appeared additive for most participants, more than additive for a sizeable minority, and competitive in very few. In the field, unlike in human laboratory studies to date, craving for cocaine and heroin is greater with the combination of drug cues and stress than with either alone. For a substantial minority of users, the combined effect may be more than additive.

Neuropsychopharmacology (2018) 43, 859-867; doi: I 0.I038/npp.2017.275; published online 6 December 2017
\end{abstract}

\section{INTRODUCTION}

Stress and drug cues are well-established factors in maintaining drug use and precipitating relapse. Laboratoryanimal studies show that the likelihood of drug-seeking behavior is increased by acute stressors (eg, tail pinching, etc) and by cues and contexts associated with drug-taking (Bossert et al, 2013; Cleck and Blendy, 2008; Crombag et al, 2008). In humans, stress and drug cues can increase craving, as demonstrated in studies conducted in the laboratory (Fox et al, 2008; Jobes et al, 2015; Ray et al, 2013; Schmidt et al, 2014) and in studies using ecological momentary assessment to collect data in drug users' natural environments (Epstein et al, 2009; Preston and Epstein, 2011). Furthermore, reactivity to stress and drug cues has been shown to predict relapse (Back et al, 2010; Kosten et al, 2006; Sinha et al, 2006).

\footnotetext{
*Correspondence: Dr K Preston, Clinical Pharmacology and Therapeutics Research Branch, NIDA Intramural Research Program, Treatment Section, 25 I Bayview Boulevard Suite 200, Baltimore, MD, USA.

Tel: +443.740.2326, Fax: +443.740.2318,

E-mail: KPRESTON@intra.nida.nih.gov

Received 6 October 2016; revised 17 October 2017; accepted 24 October 2017; accepted article preview online 6 November 2017
}

Evidence is growing that the effects of stress and drug cues on addiction are not independent. Consistent with the overlapping neurocircuitry of stress and addiction in laboratory animals (Fosnocht and Briand, 2016; Koob and Volkow, 2016; Mantsch et al, 2014), there is overlap in the interoceptive, hormonal, and physiological effects of stress and drug-associated cues in humans (Bergquist et al, 2010; Sinha et al, 2003). Perhaps even more problematic for treatment and relapse prevention is that stress and drug use interact over time to increase vulnerability to continued drug taking. Experimental evidence supports the idea that stress reactivity is altered in substance users and that combined exposure to stress and drug cues produces especially pronounced neurophysiological changes, craving, and drug seeking (Fosnocht and Briand, 2016; Koob and Volkow, 2016; Mantsch et al, 2014; Robinson and Berridge, 1993). Discussing their incentive-sensitization theory of addiction, Robinson and Berridge (1993) predicted that, because both stress and drug use activate and sensitize dopamine systems, stress will 'magnify' craving induced by drug-associated cues. Stress has since been shown to exacerbate cue-induced drugseeking in the rat reinstatement model (Banna et al, 2010; Buffalari and See, 2009; Feltenstein et al, 2011). 
Evidence that stress and cues can combine to exacerbate craving in humans, however, has been harder to find. In human laboratory studies, tobacco smokers, marijuana users, dependent drinkers, and prescription-opioid users exposed to either stressors and drug cues reported increases in craving, but none of the studies succeeded in showing that the combination induced greater craving than either of the two alone (Back et al, 2015; McRae-Clark et al, 2011; Ray et al, 2013; Thomas et al, 2011). Moran-Santa Maria et al, 2014 showed potentiation of craving in women, but not men, given yohimbine as a stressor before exposure to cocaineparaphernalia cues. In an fMRI study, Dagher et al, 2009 demonstrated stress-increased neural responses to cues in smokers, but the increase was not reflected in self-reported craving. To our knowledge, a stress-induced exacerbation of cue-induced craving in both men and women has been shown only for the odor of chocolate (Pool et al, 2015).

Another approach to studying drug craving, and its relationships with stress and cues, is ecological momentary assessment (EMA), a data collection methodology in which participants make self-reports on electronic diaries as they go about their normal activities. EMA studies have shown a strong relationship between stress and craving when both are assessed at random times in participants' natural environments (Epstein et al, 2009; Preston and Epstein, 2011). EMA also provides the opportunity to examine cue and stress exposure in context, as participants can be asked to report on their surroundings and activities as well as their moods.

We conducted a large natural-history study in which opioid-dependent polydrug users in opioid-agonist maintenance treatment carried electronic diaries for up to 16 weeks. Here, using some of the data from that study, we report that craving is greater in the combined presence of drug cues and stress than in the presence of either alonebut not for all users.

\section{MATERIALS AND METHODS}

\section{Participants}

The participants were methadone- or buprenorphinemaintained opioid-dependent polydrug users at a treatment-research clinic in Baltimore, MD. All were participating in a 46-week natural-history study of stress, geographical location, and drug use. Our prior publications of data from a subset of participants in this study focused primarily on ambulatory physiological monitoring (Hossain et al, 2014; Kennedy et al, 2015; Rahman et al, 2014) and an examination of the relationship between stress and drug use (Furnari et al, 2015).

During screening, participants completed the Addiction Severity Index (ASI; McLellan et al, 1985 and the Diagnostic Interview Schedule (DIS IV; Robins et al, 1995) and were given physical examinations and psychological testing. The main inclusion criteria were: age 18 to 75 years, physical dependence on opioids, and (due to the behavioralgeography focus of the parent study) residence in Baltimore City or one of the surrounding counties. The main exclusion criteria were: history of any DSM-IV psychotic disorder, bipolar disorder, or current Major Depressive Disorder; current dependence on alcohol or sedative-hypnotics; cognitive impairment precluding informed consent or valid self-report; conditions that preclude urine collection; or medical illness or medications that would compromise research participation. This study was reviewed and approved by the National Institutes of Health Addictions Institutional Review Board. Participants gave prior written informed consent and were paid for completing the research components of this study.

\section{Procedure}

Participants attended clinic 5 to 7 days a week; methadone or buprenorphine was administered daily, and individual counseling was given weekly. Urine was collected under observation and screened for illicit drugs thrice weekly.

After 2 weeks of treatment, each participant was trained to use a smartphone as an electronic diary (ED) and then carried it for up to 16 weeks, during weeks 3-18 of the study. The EDs were programmed with our electronic-diary software (Vahabzadeh et al, 2004). Participants received 3 random prompts (RPs) per day, timed to occur only during self-reported waking hours, which were programmed into the ED. Participants rated how much they craved opioids and cocaine, stress level, and a series of 28 mood adjectives. They also indicated whom they were with, what they were doing, and where they were from drop-down lists. Participants were asked if they had seen, been offered, or seen others using an opioid, cocaine, cannabis, methamphetamine, alcohol, or tobacco in the last $5 \mathrm{~min}$ or since they got to their present location. Participants made two additional types of entries not reported here: event-contingent entries, which they initiated whenever they felt 'more stressed, overwhelmed, or anxious than usual' or any time they used a drug for nonmedical purposes, and end-of-day entries. We analyzed RP ratings of craving rather than participantinitiated reports of actual drug use, because the craving ratings were the most proximal and sensitive readout of what we wanted to assess. Not all instances of craving result in drug use, especially for users who have decided to enroll in treatment. For those users, however, craving itself can be an aversive experience (Tiffany and Wray, 2012). Even instances of craving that are not strongly aversive are likely to be unwanted distractions during recovery. Therefore, we consider craving inherently worthy of clinical and scientific attention.

The participants were paid $\$ 10$ each week for completing at least $82 \%$ of their random prompts, or were given a warning if they did not meet the criterion. If the participant did not meet the $82 \%$ completion criterion for 2 weeks after being warned, they were removed from the study and assisted with transfer into community-based addiction treatment.

\section{Data Analysis}

To create a predictor for drug-cue exposure, we coded participants' responses as ' 1 ' when they reported having seen or been offered opioids, cocaine, cannabis, methamphetamine, alcohol, or tobacco, and ' 0 ' if not.

To check for collinearity between drug-cue exposure and our other momentary predictor (stress, rated 1-5), we examined the overall distribution of cells in a $2 \times 5$ table across all random-prompt entries. We also quantified the 
association, using a random-intercept, random-slopes model in SAS Proc Mixed in which cue exposure was the predictor and stress rating was the outcome. In this and all our other mixed models, we used an 'autoregression+noise' error structure (Schwartz and Stone, 2007), in which a spatialpower function accounts for the uneven intervals between entries.

To test our main hypotheses-that heroin and cocaine craving would be greater in the combined presence of stress and drug cues than in the presence of only one or neither (ie, that stress and cue effects would be at least additive)-we ran two models, one for heroin craving, one for cocaine craving. We constructed the models to distinguish person-level differences from within-person relationships, the latter being a stronger basis for conclusions about how changes in a predictor lead to changes in outcome. Mixed models can account for person-level differences when participants differ widely on the outcome variable, but do not automatically account for the possibility that people differ widely on predictors (van de Pol and Wright, 2009). We calculated person-level means for stress severity and drug-cue exposure (the latter was the 'mean' of each participant's momentary 0 's and 1's), and we used those means to create personmean-centered versions of each of the momentary predictors. Each model thus contained the following six predictors: person-centered momentary stress rating, person-centered momentary cue exposure, and the interaction of the two momentary predictors; person-level mean stress, person level 'mean' cue exposure, and the interaction of the two personlevel predictors. Type 3 tests for the first three predictors reflect within-person relationships across time, controlling for person-level differences. The Stress $\times$ Cue interaction term denotes additive effects if it is not different from 0 , more-than-additive (ie, synergistic) effects if significantly greater than 0 , and competitive effects if significantly less than 0 .

For all models, we specified denominator degrees of freedom using the conservative method recommended by Bolger and Laurenceau (2013), reflecting the number of participants rather than the number of time points. Alpha was set at.05, two-tailed, for all analyses.

To show the degree of heterogeneity across participants, we plotted histograms of the model-derived Stress $\times$ Cue parameter estimates (empirical best linear unbiased predictors; EBLUPS) for all participants, and we noted descriptively how many participants showed patterns of results consistent with the group means (Branch, 2014). All analyses were performed using SAS, version 9.4 (SAS Institute, Cary, NC).

\section{RESULTS}

\section{Participants and EMA Reporting and Compliance}

Data were collected between 14 July 2009 and 4 June 2015 . Of 226 individuals who signed consent, 182 provided EMA data for at least 2 weeks, 12 provided EMA data for less than 2 weeks, and 32 left the study before providing any EMA data. The demographic and drug-use histories of the 182 participants whose data are reported are shown in Table 1. They provided EMA data for a mean $( \pm S D)$ of $101.0( \pm 26.6)$ days (range 14-156) over 18,379 study days. On average, they
Table I Clinical and Demographic Characteristics

N

Opioid-agonist maintenance

Methadone

$107(59 \%)$

Buprenorphine

$75(41 \%)$

Age mean (SD)

$41.9(9.5)$

Sex

Male

135 (74\%)

Female

$47(26 \%)$

Race

African American

European American

multiracial

Years of education: mean (SD)

Marital status

Married

$13 \%$

Never married

$61 \%$

Separated/divorced/widowed

$26 \%$

Employment status

Full-time

$46 \%$

Part-time

$23 \%$

Unemployed

$25 \%$

Retired/disability/controlled environment

$6 \%$

Days used in past 30 before enrollment

Heroin: mean (SD)

$19.3(11.9)$

Cocaine: mean (SD)

Opioids other than heroin: mean (SD)

$8.1(10.3)$

\section{Years of use}

Heroin: mean (SD)

$14.5(10.2)$

Cocaine: mean (SD)

Opioids other than heroin: mean (SD)

$\begin{array}{ll}\text { Route of administration } & \\ \text { Heroin }(n=176) & \\ \text { Intranasal } & 61 \% \\ \text { Intravenous } & 39 \% \\ \text { Cocaine }(n=136) & \\ \text { Smoking } & 54 \% \\ \text { Intranasal } & 24 \% \\ \text { Intravenous } & 22 \% \\ \text { Opioids other than heroin }(n=\mid 43) & \\ \text { Oral } & 91 \% \\ \text { Intranasal } & 7 \% \\ \text { Smoking } & 2 \%\end{array}$


completed $2.4( \pm 0.4)$ random-prompt entries per day for a total of 44,326 entries, with an overall compliance rate of $81 \%$.

In event-contingent entries (not analyzed here), they made a total of 2763 drug-use reports and 1787 stress reports; 33 (18.1\%) made no drug reports, and 24 (13.2\%) made no stress reports. An event-contingent entry for drug use was made every 6.7 days ( 0.15 per day), and an event-contingent entry for stress was made every 10.3 days ( 0.10 stress reports per day).

In the 44,326 random-prompt entries, as stress ratings increased from 1 to 5 , the corresponding percentages of drug-cue reports were $31 \%, 42 \%, 38 \%, 35 \%$, and $41 \%$. Thus, although drug-cue exposure did predict higher stress ratings in a random-effects model (least-squares means $1.61 \pm .05$ without drug cues, $1.70 \pm 0.05$ with drug cues; F $(1,178)=8.85, p=0.003)$, the two were not so strongly collinear as to preclude their simultaneous use as predictors of craving.

\section{Stress $\times$ Cue Effects on Momentary Craving for Heroin}

The output from this model is shown in Table 2, and the within-person Stress $\times$ Cue interaction (row 4 of the table) is graphed in Figure 1a. Controlling for between-person differences in mean stress ratings, frequency of drug-cue exposure, and their interaction, there were significant positive main effects of momentary stress and momentary drug-cue exposure. The interaction of the two appeared to be positive, as reflected in the steeper slope for the 'Drug cue present' in Figure 1a. This interaction was not statistically greater than $0(\mathrm{~F}(1,178)=2.11, p=0.148)$, but the confidence interval $(-0.007-0.044)$ was predominantly greater than 0 . While not statistically significant, the interaction effect is in the direction that suggests a synergistic interaction and is of a magnitude that is nearly identical to the statistically significant corresponding effect in the model predicting cocaine craving (see below).

The tests for random effects in Table 2 show statistically significant between-person variability in heroin craving (at its intercept) and in the main and interactive effects of stress and cue exposure on heroin craving. This can be seen more clearly in Figure 2a, a histogram of the person-specific estimates for the Stress $\times$ Cue interaction. Slopes greater than 0 indicate exacerbation of the cue effects by stress (or vice versa); a slope of 0 indicates that the effects of the two predictors are no more than additive; slopes less than 0 indicate that cue exposure suppresses the effects of stress (or vice versa). In our sample, values tended to be either above 0 or very near it. (There was one exception, visible on the lower left of Figure 2a: a participant who reported heroin craving only on the 6/41 occasions when he was stressed in the absence of cues, not on the 20/45 occasions when he was stressed in the presence of cues.)

\section{Cue $\times$ Stress Effects on Momentary Craving for Cocaine}

The output from this model is shown in Table 3, and the within-person Stress $\times$ Cue interaction (row 4 of the table) is graphed in Figure 2a. Controlling for between-person differences in mean stress ratings, frequency of drug-cue exposure, and their interaction, there were significant

Table 2 Parameter Estimates for Heroin Craving as Function of Stress, Drug-cue Exposure, and their Interaction

\begin{tabular}{|c|c|c|c|c|c|c|}
\hline Fixed effects & Estimate & (SE) & Type $3 \mathrm{~F}^{\mathrm{a}}$ & $p$ & Lower CL95 & Upper CL95 \\
\hline Intercept & 0.834 & 0.107 & - & - & 0.624 & 1.044 \\
\hline Momentary stress & 0.085 & 0.010 & 66.16 & $<0.0001$ & 0.064 & 0.106 \\
\hline Momentary drug cues & 0.094 & 0.014 & 44.14 & $<0.0001$ & 0.066 & 0.122 \\
\hline Momentary Stress $\times$ Cues $^{b}$ & 0.019 & 0.013 & 2.11 & 0.148 & -0.007 & 0.044 \\
\hline Mean stress (person-level) & 0.245 & 0.066 & |3.7| & 0.0003 & 0.114 & 0.376 \\
\hline Random effects ${ }^{d}$ & Estimate & (SE) & $z$ & $p$ & Lower CL95 & Upper CL95 \\
\hline Variance of intercept & 0.144 & 0.017 & 8.37 & $<0.0001$ & 0.116 & 0.185 \\
\hline Variance of slope for stress & 0.015 & 0.002 & 8.13 & $<0.0001$ & 0.123 & 0.020 \\
\hline
\end{tabular}

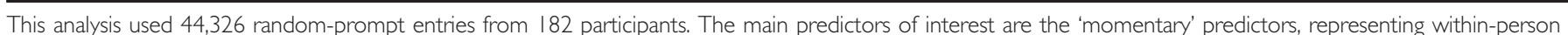

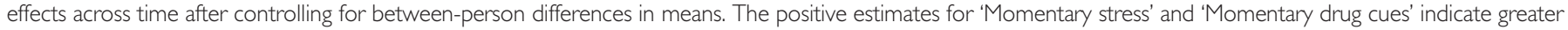
heroin craving as a function of stress or drug-cue exposure.

a Degrees of freedom ( | |78).

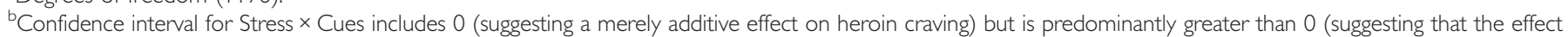
may be synergistic).

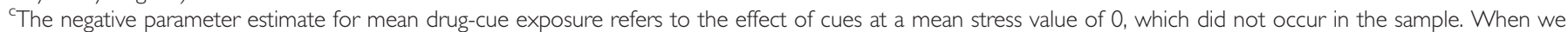

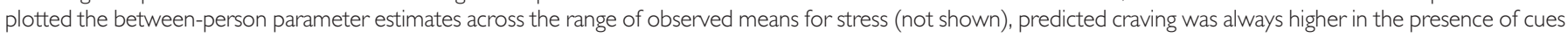
than in their absence.

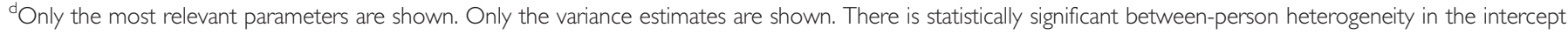
and each of the three within-person momentary effects. 

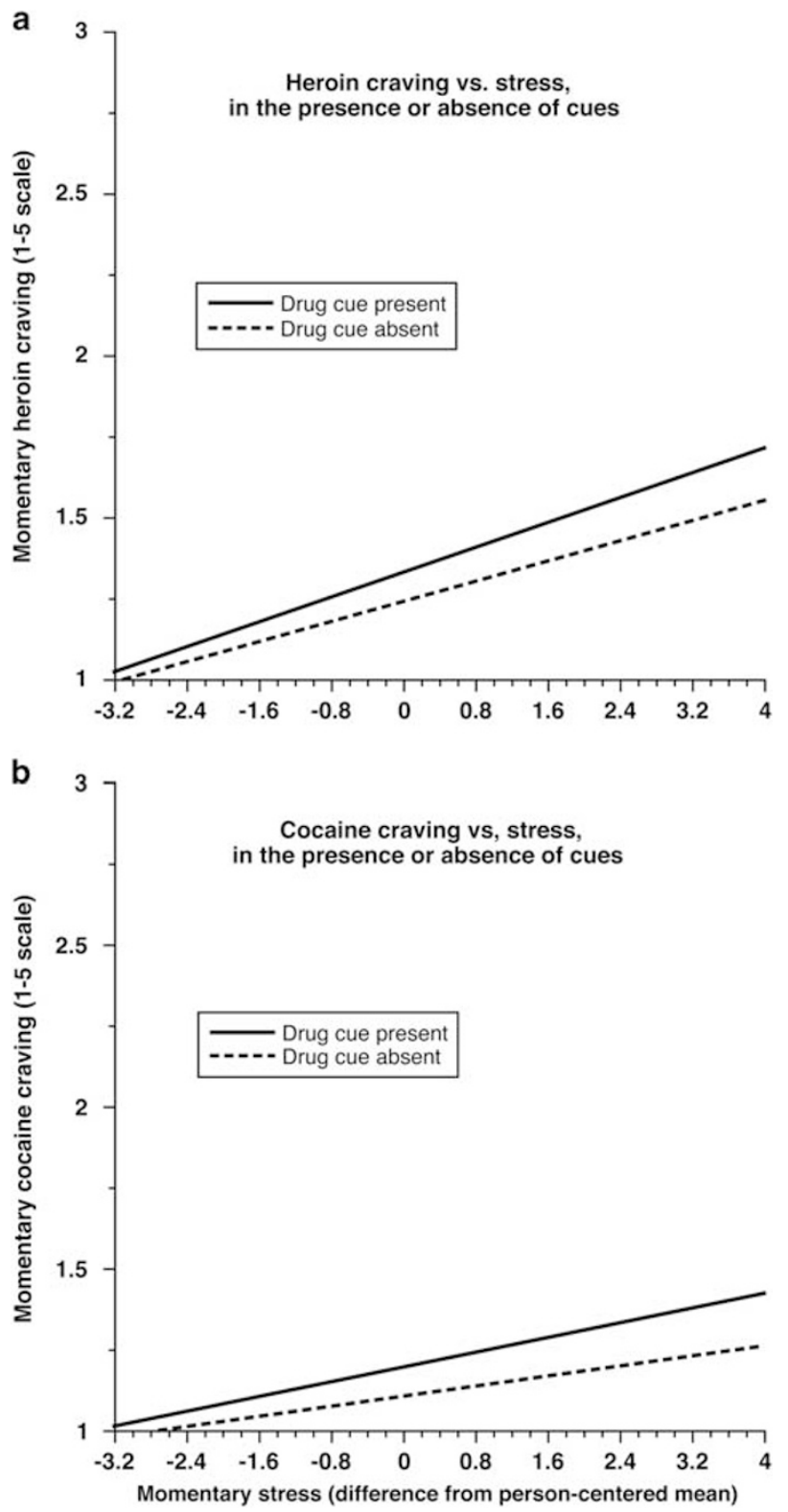

Figure I Model-predicted EMA ratings of craving for heroin (a) or cocaine (b) on a I to 5 scale (I indicating no craving) to momentary stress, by presence or absence of drug cues, for the average participant, based on 44,326 random-prompt entries made by 182 drug users. Momentary stress is person-centered (ie, each momentary value has had the person-level mean subtracted) to control for between-person differences in stress. Thus, 0 on the $x$-axis indicates that the person is at his or her mean level of stress. Each line is the slope from the interaction term of the within-subject predictors in the model, with the between-subject predictors (mean stress and 'mean' drug-cue exposure) set to their sample means. For heroin, the slope for the interaction was 0.018 (Table 2, line 4), (CL95 - 0.007-0.044). For cocaine, the slope for the interaction was 0.019 (Table 3, line 4), (CL95 $0.001-0.036)$.

positive main effects of momentary stress and momentary drug-cue exposure-along with a positive/synergistic interaction of the two, $\mathrm{F}(1,178)=4.39, p=0.038$, denoting a more-than-additive effect of stress and cues on cocaine craving.

The tests for random effects in Table 3 show statistically significant between-person variability in cocaine craving (at its intercept) and in the main and interactive effects of stress
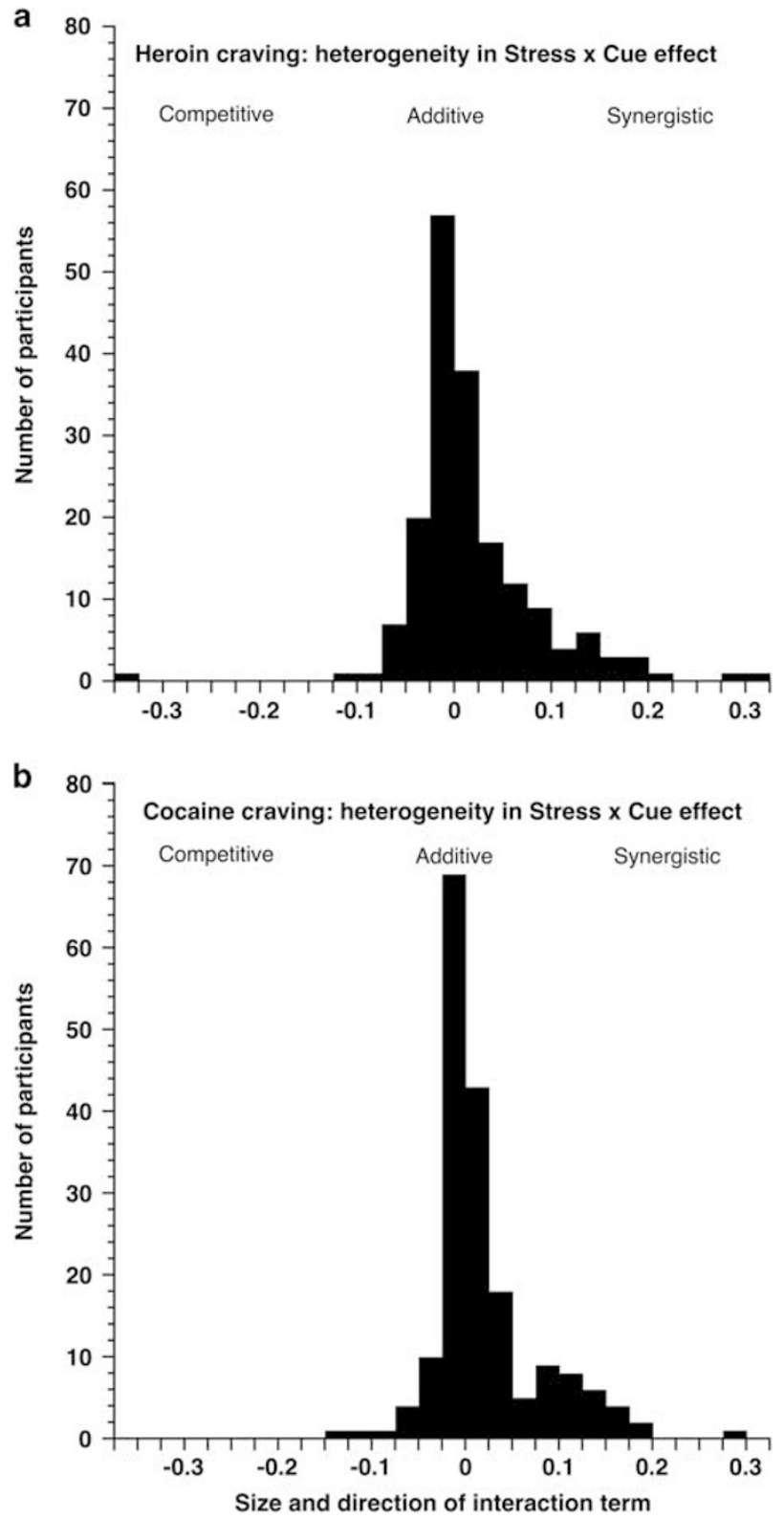

Figure 2 Histograms of the directions and sizes of Stress $\times$ Cue interactions on EMA ratings of craving for heroin or cocaine in 182 users, taken from variance-components estimates of SAS Proc Mixed models. The distributions show both the heterogeneity of the interaction and its tendency to be either positive or close to 0 . (a) For heroin craving, the interaction was positive in 94 participants (52\%) and was negative but near 0 in all but one of the other 88 . (Significance tests should be interpreted with caution, but were $<0.05$ for 9 of the positive slopes and 3 of the negative slopes.) (b) For cocaine craving, the interaction was positive in 95 participants (52\%) and was negative but near 0 in the other 85. (Significance tests should be interpreted with caution, but were $<0.05$ for 25 of the positive slopes and 9 of the negative slopes.)

and cues. Figure $2 \mathrm{~b}$ shows person-specific slopes for the Stress $\times$ Cue interaction; they tended to be either above 0 or very near it.

\section{Raw Mean Data at the Person Level}

To check the 'ground truth' of our model-derived estimates, we examined raw person-level data, as suggested by Branch 
Table 3 Parameter Estimates for Cocaine Craving as Function of Stress, Drug-Cue Exposure, and their Interaction

\begin{tabular}{|c|c|c|c|c|c|c|}
\hline Intercept & 1.060 & 0.065 & - & - & 0.931 & 1.188 \\
\hline Momentary drug cues & 0.087 & 0.014 & 37.18 & $<0.0001$ & 0.059 & 0.115 \\
\hline Momentary Stress $\times$ Cues & 0.019 & 0.009 & 4.39 & 0.038 & 0.001 & 0.036 \\
\hline Mean stress (person-level) & 0.011 & 0.039 & 0.08 & 0.78 & -0.065 & 0.087 \\
\hline Mean Stress $\times$ Mean Cues (person-level) ${ }^{c}$ & 0.282 & 0.081 & 12.27 & 0.0006 & 0.123 & 0.442 \\
\hline Random effects & Estimate & (SE) & $\mathbf{z}$ & $p$ & Lower CL95 & Upper CL95 \\
\hline Variance of intercept & 0.080 & 0.010 & 8.33 & $<0.000$ । & 0.064 & 0.103 \\
\hline Variance of slope for stress & 0.006 & 0.001 & 7.41 & $<0.000$ । & 0.005 & 0.008 \\
\hline Variance of slope for cues & 0.026 & 0.004 & 6.91 & $<0.0001$ & 0.020 & 0.036 \\
\hline
\end{tabular}

Details are the same as those for Table 2 .

${ }^{a}$ Degrees of freedom (1 |78).

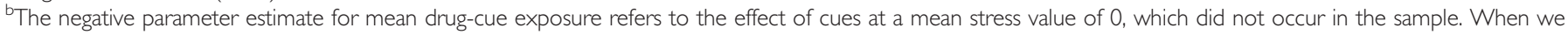
plotted the between-person parameter estimates across the range of observed means for stress (not shown), predicted craving was always higher in the presence of cues than in their absence.

'The person-level interaction between stress and cues reflects a tendency for overall cocaine craving to be especially high in participants who experienced high overall levels of both stress and cue exposure (consistent with an exacerbatory interaction). A similar pattern was present for heroin (Table 2), but was not statistically significant.

(2014). For simplicity, we assessed each participant's mean craving for heroin and cocaine across four conditions: cues present, stress rating $>1$, both, and neither. By doing so, we were able to confirm that 'exacerbating' interactions of stress and cues were qualitatively observable in a large plurality of individual participants ( $43 \%$ of participants showed the 'exacerbation' pattern for heroin craving, 38\% for cocaine craving). Those who did not show the exacerbation pattern had relatively flat ratings of craving across the four conditions, but not opposing patterns. 'Exacerbators' and 'non-exacerbators' showed similar ranges of craving scores and stress ratings. These findings (not shown) are implied by the results of the models.

\section{DISCUSSION}

Craving is a key feature of addiction: it predicts treatment outcome (Higley et al, 2011; Tsui et al, 2014) and has been added as a criterion for diagnosis of substance-use disorders in DSM-5 (Murphy et al, 2014). Understanding the factors that influence craving could help improve treatment outcomes and relapse prevention.

In this study we investigated relationships among stress, cues, and craving in our opioid-dependent, polydrug-using patients. Although we cannot draw causal conclusions from our data, the 'stress and craving ' results replicate our earlier work (Preston and Epstein, 2011) and are consistent with a large body of research showing that craving and the likelihood of relapse are greater in the presence of stress (Breese et al, 2005; Law et al, 2016). The 'cue and craving' results are consistent with a parallel (though more mixed) body of research on cues (Papachristou et al, 2014; Shiffman et al, 2015; Witteman et al, 2015). The small but reliable association between stress and the presence of drug cues is consistent with findings in laboratory studies that drug-cue exposure is itself stressful to people who are trying to abstain from use (Sinha et al, 2006; Sinha et al, 2003).

Our main question was whether craving would be exacerbated (ie, increased at least additively, perhaps more) when stress and drug cues were present together. To our knowledge, the only prior EMA study to examine such a question systematically was a study of smokers, in whom the pattern seemed to be not one of exacerbation, but suppression or mutual dampening (Shiffman and Gwaltney, 2008). However, the predictor tested in that study was not stress per se; it was negative affect, which was operationalized to include low-arousal states such as 'sad' and 'miserable.' It seems plausible that cue exposure could have different effects during low-arousal negative affect than during the higharousal, sometimes mixed-valence state (Folkman, 2008) that is stress.

Stress itself, however, has not reliably exacerbated the effects of drug cues on craving in human laboratory studies as it does in animal studies (Banna et al, 2010; Buffalari and See, 2009; Feltenstein et al, 2011). For example, Back et al (2015) exposed prescription-opioid abusers and controls to a stressor (the Trier Social Stress Task, TSST) and drug cues (an audio script, paraphernalia, and video); the stressor increased ratings of craving, and the cues increased ratings of craving, but there was no sign of synergism (ie, no statistical interaction) between the two. McRae-Clark et al (2011) conducted a similar study in marijuana-dependent participants: cues and the TSST each increased marijuana craving, but the combination did not increase it further. Ray et al (2013) exposed smokers to personalized stress-imagery scripts followed by smoking cues (holding and smelling an unlit cigarette); each increased craving compared to neutral conditions, but cues did not exacerbate stress-induced craving. Thomas et al (2011) presented dependent drinkers with the TSST and an alcohol cue (a beverage that they were 
asked to hold and sniff). In that study, stress did not increase craving, although the alcohol cue did increase craving (with or without stress).

The absence of exacerbatory interaction (or even an additive effect) of stress and cues in human laboratory studies could reflect suppression of one effect by the otherstress may have distracted people from cues and vice versa. It could also reflect ceiling effects on the amount of craving most people are likely to experience in a laboratory; Thomas et al (2011) note in their literature review that stress in a laboratory setting failed to induce craving for alcohol in about half of the relevant published studies. Further complications might include differences among drugs (stress-induced craving seems more reliable in people dependent on opioids or cocaine; Fox et al, 2008; Jobes et al, 2011; Schmidt et al, 2014; Sinha et al, 2006) and among users (for drinkers, individual differences in coping skills can modulate responses to different types of stressors and cues; Snelleman et al, 2014). One human laboratory study did show a combined effect of stress and drug cues (on cocaine craving). But that study used yohimbine as the stressor (Moran-Santa Maria et al, 2014), rather than the more typically used TSST. Yohimbine has been used as a 'pharmacological stressor' in rodent models of relapse (Banna et al, 2010; Buffalari and See, 2009; Feltenstein et al, 2011), but recent data have cast doubt on whether it truly acts as a stressor in rodents-for example, it does not produce conditioned place aversion, as do other stressors (Chen et al, 2015). In the Moran-Santa Maria et al, study, yohimbine did increase ratings of 'anxiety' in cocainedependent women (not in controls), but apparently did not increase ratings of 'distress' on the same questionnaire.

The main contribution of our EMA data is to show that stress and cue exposure can have at least an additive effectand, for many users, more than additive-on cocaine craving, and possibly on heroin craving, in daily life.

Stress and cue do not appear to dampen each other's effects, as might have been inferred from the available humanlaboratory data-at least, not in the overwhelming majority of users. Because our analytic approach allowed us to document and quantify between-person heterogeneity, the current findings complement our prior finding that the effect of stress on actual drug use is also heterogeneous (Furnari et al, 2015).

We did not make direct comparisons between heroin and cocaine craving, partly because all our participants used opioids and only a subset used cocaine. However, the data in Figure 1 (and the parameter estimates) suggest that momentary stress had a stronger main effect on craving for heroin than for cocaine. This is consistent with a finding, from one of our earlier EMA studies, that event-contingent reports of cocaine use (compared to reports of heroin use) were associated with a greater likelihood of almost every daily-life activity we assessed (socializing, working, chores, shopping, watching TV) except one: being in an argument, which was associated with heroin use (Epstein et al, 2008). We speculate that heroin, more than cocaine, is wanted and used for its ability to soothe stress.

One limitation of our study is its observational design, along with the cross-sectional nature of each of our momentary assessments. These limitations preclude firm conclusions about causality. It seems very likely that craving could cause exposure to (or heightened awareness of) drug cues, and also that craving could cause stress. In future analyses, we may be able to draw additional conclusions by examining lagged associations. Another limitation is that our participants rarely reported very high levels of either craving or stress, and we cannot be certain that the low intensities reported here are clinically significant. In EMA data from a different but demographically similar group, we have shown that the mood changes, craving changes, and exposures our participants report in RP entries do predict actual drug use within the next few hours (Epstein et al, 2009; Preston and Epstein, 2011; Preston et al, 2009). That association was present despite the fact that our random prompts, in the earlier studies and this one, cover only the participant's selfreported normal waking hours. Cue/stress/craving associations that occur very late at night are not detectable in our RP entries.

Despite these limitations, we have demonstrated that craving for opioids and cocaine is exacerbated in the simultaneous presence of drug cues and stress compared to the presence of either alone. The ambulatory nature of our assessments enabled us to detect relationships that have been elusive in controlled human-laboratory settings. These results are consistent with behavioral and neurobiological research on addiction and stress. An important next step is to examine sources of heterogeneity with idiographic analyses (Hekler et al, 2016) so treatment can be more effectively personalized.

\section{FUNDING AND DISCLOSURE}

This study was supported by the Intramural Research Program of the National Institute on Drug Abuse, National Institutes of Health. The funding source played no role in study design; in the collection, analysis, and interpretation of data; in the writing of the report; or in the decision to submit the paper for publication. The authors do not have any competing financial interests related to the research presented. The authors declare no conflict of interest.

\section{ACKNOWLEDGMENTS}

Many thanks to our peer reviewers, especially Dr Joseph Schwartz, who de-anonymized himself during review to provide extensive statistical guidance. If any statistical shortcomings remain, responsibility lies with the authors.

\section{REFERENCES}

Back SE, Gros DF, Price M, LaRowe S, Flanagan J, Brady KT et al (2015). Laboratory-induced stress and craving among individuals with prescription opioid dependence. Drug Alcohol Depend 155: 60-67.

Back SE, Hartwell K, DeSantis SM, Saladin M, McRae-Clark AL, Price KL et al (2010). Reactivity to laboratory stress provocation predicts relapse to cocaine. Drug Alcohol Depend 106: 21-27.

Banna KM, Back SE, Do P, See RE (2010). Yohimbine stress potentiates conditioned cue-induced reinstatement of heroinseeking in rats. Behav Brain Res 208: 144-148.

Bergquist KL, Fox HC, Sinha R (2010). Self-reports of interoceptive responses during stress and drug cue-related experiences in cocaine- and alcohol-dependent individuals. Exp Clin Psychopharmacol 18: 229-237. 
Bolger N, Laurenceau J-P (2013). Intensive Longitudinal Methods: An Introduction to Diary and Experience Sampling Research. Guilford: New York.

Bossert JM, Marchant NJ, Calu DJ, Shaham Y (2013). The reinstatement model of drug relapse: recent neurobiological findings, emerging research topics, and translational research. Psychopharmacology 229: 453-476.

Branch M (2014). Malignant side effects of null-hypothesis significance testing. Theor Psychol 24: 256-277.

Breese GR, Chu K, Dayas CV, Funk D, Knapp DJ, Koob GF et al (2005). Stress enhancement of craving during sobriety: a risk for relapse. Alcohol Clin Exp Res 29: 185-195.

Buffalari DM, See RE (2009). Footshock stress potentiates cueinduced cocaine-seeking in an animal model of relapse. Physiol Behav 98: 614-617.

Chen YW, Fiscella KA, Bacharach SZ, Tanda G, Shaham Y, Calu DJ (2015). Effect of yohimbine on reinstatement of operant responding in rats is dependent on cue contingency but not food reward history. Addict Biol 20: 690-700.

Cleck JN, Blendy JA (2008). Making a bad thing worse: adverse effects of stress on drug addiction. J Clin Invest 118: 454-461.

Crombag HS, Bossert JM, Koya E, Shaham Y (2008). Contextinduced relapse to drug seeking: a review. Philos Trans $R$ Soc Lond B Biol Sci 363: 3233-3243.

Dagher A, Tannenbaum B, Hayashi T, Pruessner JC, McBride D (2009). An acute psychosocial stress enhances the neural response to smoking cues. Brain Res 1293: 40-48.

Epstein DH, Willner-Reid J, Lin JL, Vahabzadeh M, Preston KL (2008). The Who, What, and Where of Drug Use and Craving. American Psychological Associaton Convention: Boston, MA.

Epstein DH, Willner-Reid J, Vahabzadeh M, Mezghanni M, Lin JL, Preston KL (2009). Real-time electronic diary reports of cue exposure and mood in the hours before cocaine and heroin craving and use. Arch Gen Psychiatry 66: 88-94.

Feltenstein MW, Henderson AR, See RE (2011). Enhancement of cue-induced reinstatement of cocaine-seeking in rats by yohimbine: sex differences and the role of the estrous cycle. Psychopharmacology 216: 53-62.

Folkman S (2008). The case for positive emotions in the stress process. Anxiety Stress Coping 21: 3-14.

Fosnocht AQ, Briand LA (2016). Substance use modulates stress reactivity: behavioral and physiological outcomes. Physiol Behav 166: 32-42.

Fox HC, Hong KI, Siedlarz K, Sinha R (2008). Enhanced sensitivity to stress and drug/alcohol craving in abstinent cocaine-dependent individuals compared to social drinkers. Neuropsychopharmacology 33: 796-805.

Furnari M, Epstein DH, Phillips KA, Jobes ML, Kowalczyk WJ, Vahabzadeh M et al (2015). Some of the people, some of the time: field evidence for associations and dissociations between stress and drug use. Psychopharmacology 232: 3529-3537.

Hekler EB, Michie S, Pavel M, Rivera DE, Collins LM, Jimison HB et al (2016). Advancing models and theories for digital behavior change interventions. Am J Prev Med 51: 825-832.

Higley AE, Crane NA, Spadoni AD, Quello SB, Goodell V, Mason BJ (2011). Craving in response to stress induction in a human laboratory paradigm predicts treatment outcome in alcoholdependent individuals. Psychopharmacology 218: 121-129.

Hossain SM, Ali AA, Rahman M, Ertin E, Epstein D, Kennedy A et al (2014). Identifying drug (cocaine) intake events from acute physiological response in the presence of free-living physical activity. IPSN 2014: 71-82.

Jobes ML, Aharonovich E, Epstein DH, Phillips KA, Reamer D, Anderson $\mathrm{M}$ et al (2015). Effects of prereactivation propranolol on cocaine craving elicited by imagery script/cue sets in opioid-dependent polydrug users: a randomized study. J Addict Med 9: 491-498.

Jobes ML, Ghitza UE, Epstein DH, Phillips KA, Heishman SJ, Preston KL (2011). Clonidine blocks stress-induced craving in cocaine users. Psychopharmacology 218: 83-88.

Kennedy AP, Epstein DH, Jobes ML, Agage D, Tyburski M, Phillips KA et al (2015). Continuous in-the-field measurement of heart rate: correlates of drug use, craving, stress, and mood in polydrug users. Drug Alcohol Depend 151: 159-166.

Koob GF, Volkow ND (2016). Neurobiology of addiction: a neurocircuitry analysis. Lancet Psychiatry 3: 760-773.

Kosten TR, Scanley BE, Tucker KA, Oliveto A, Prince C, Sinha R et al (2006). Cue-induced brain activity changes and relapse in cocaine-dependent patients. Neuropsychopharmacology 31: 644-650.

Law B, Gullo MJ, Daglish M, Kavanagh DJ, Feeney GF, Young RM et al (2016). Craving mediates stress in predicting lapse during alcohol dependence treatment. Alcohol Clin Exp Res 40: 1058-1064.

Mantsch JR, Vranjkovic O, Twining RC, Gasser PJ, McReynolds JR, Blacktop JM (2014). Neurobiological mechanisms that contribute to stress-related cocaine use. Neuropharmacology $76(\mathrm{Pt} \quad \mathrm{B})$ : 383-394.

McLellan AT, Luborsky L, Cacciola J, Griffith J, Evans F, Barr HL et al (1985). New data from the Addiction Severity Index: reliability and validity in three centers. J Nerv Ment Dis 173: 412-423.

McRae-Clark AL, Carter RE, Price KL, Baker NL, Thomas S, Saladin ME et al (2011). Stress- and cue-elicited craving and reactivity in marijuana-dependent individuals. Psychopharmacology 218: 49-58.

Moran-Santa Maria MM, McRae-Clark A, Baker NL, Ramakrishnan V, Brady KT (2014). Yohimbine administration and cue-reactivity in cocaine-dependent individuals. Psychopharmacology 231: 4157-4165.

Murphy CM, Stojek MK, Few LR, Rothbaum AO, Mackillop J (2014). Craving as an alcohol use disorder symptom in DSM-5: an empirical examination in a treatment-seeking sample. Exp Clin Psychopharmacol 22: 43-49.

Papachristou H, Nederkoorn C, Giesen JC, Jansen A (2014). Cue reactivity during treatment, and not impulsivity, predicts an initial lapse after treatment in alcohol use disorders. Addict Behav 39: 737-739.

Pool E, Brosch T, Delplanque S, Sander D (2015). Stress increases cue-triggered "wanting" for sweet reward in humans. J Exp Psychol Anim Learn Cogn 41: 128-136.

Preston KL, Epstein DH (2011). Stress in the daily lives of cocaine and heroin users: relationship to mood, craving, relapse triggers, and cocaine use. Psychopharmacology 218: 29-37.

Preston KL, Vahabzadeh M, Schmittner J, Lin JL, Gorelick DA, Epstein DH (2009). Cocaine craving and use during daily life. Psychopharmacology 207: 291-301.

Rahman M, Bari R, Ali AA, Sharmin M, Raij A, Hovsepian K et al (2014). Are we there yet? Feasibility of continuous stress assessment via wireless physiological sensors. $A C M B C B$ 2014: 479-488.

Ray LA, Lunny K, Bujarski S, Moallem N, Krull JL, Miotto K (2013). The effects of varenicline on stress-induced and cue-induced craving for cigarettes. Drug Alcohol Depend 131: 136-142.

Robins LN, Cottler LB, Bucholz KK, Compton WM III (1995). The Diagnostic Interview Schedule, Version IV. Washington University: St. Louis, MO.

Robinson TE, Berridge KC (1993). The neural basis of drug craving: an incentive-sensitization theory of addiction. Brain Res Brain Res Rev 18: 247-291.

Schmidt A, Borgwardt S, Gerber H, Wiesbeck GA, Schmid O, Riecher-Rossler A et al (2014). Acute effects of heroin on negative emotional processing: relation of amygdala activity and stressrelated responses. Biol Psychiatry 76: 289-296.

Schwartz JE, Stone AA (2007). The analysis of real-time momentary data: a practical guideIn:Stone AA, Shiffman S, Atienza AA, Nebeling L(eds) The Science of Real-Time Data Capture: SelfReports in Health Research. Oxford University Press: New York, NY. 
Shiffman S, Gwaltney CJ (2008). Does heightened affect make smoking cues more salient? J Abnorm Psychol 117: 618-624.

Shiffman S, Li X, Dunbar MS, Tindle HA, Scholl SM, Ferguson SG (2015). Does laboratory cue reactivity correlate with real-world craving and smoking responses to cues? Drug Alcohol Depend 155: $163-169$.

Sinha R, Garcia M, Paliwal P, Kreek MJ, Rounsaville BJ (2006). Stress-induced cocaine craving and hypothalamic-pituitaryadrenal responses are predictive of cocaine relapse outcomes. Arch Gen Psychiatry 63: 324-331.

Sinha R, Talih M, Malison R, Cooney N, Anderson GM, Kreek MJ (2003). Hypothalamic-pituitary-adrenal axis and sympathoadreno-medullary responses during stress-induced and drug cue-induced cocaine craving states. Psychopharmacology 170: $62-72$.

Snelleman M, Schoenmakers TM, van de Mheen D (2014). The relationship between perceived stress and cue sensitivity for alcohol. Addict Behav 39: 1884-1889.

Thomas SE, Randall PK, Brady K, See RE, Drobes DJ (2011). An acute psychosocial stressor does not potentiate alcohol cue reactivity in non-treatment-seeking alcoholics. Alcohol Clin Exp Res 35: 464-473.

Tiffany ST, Wray JM (2012). The clinical significance of drug craving. Ann N Y Acad Sci 1248: 1-17.

Tsui JI, Anderson BJ, Strong DR, Stein MD (2014). Craving predicts opioid use in opioid-dependent patients initiating buprenorphine treatment: a longitudinal study. Am J Drug Alcohol Abuse 40: 163-169.

Vahabzadeh M, Epstein DH, Mezghanni M, Lin J-L, Preston KL (2004). An electronic diary software for ecological momentary assessment (EMA) in clinical trials. Proceedings of the 17th IEEE Symposium on Computer-Based Medical Systems (CBMS); 25-25 June 2004; Bethesda, MD, USA. IEEE, Bethesda, MD, USA.

van de Pol M, Wright J (2009). A simple method for distinguishing within- versus between-subject effects using mixed models. Anim Behav 77: 753-758.

Witteman J, Post H, Tarvainen M, de Bruijn A, Perna Ede S, Ramaekers JG et al (2015). Cue reactivity and its relation to craving and relapse in alcohol dependence: a combined laboratory and field study. Psychopharmacology 232: 3685-3696. 